\title{
Impact Of Educational Program About Nutrition That Enhances The Immunity Among Older Adults At Qena City, Egypt
}

\section{Nadia Omar Emam Abdelnasser ${ }^{1 *}$, Hoda Diab Fahmy Ibrahim ${ }^{2}$, HuiJun Chih ${ }^{3}$, Asmaa Kamal Hassan ${ }^{2}$, Mohamed Kamal Alsayed Youssef ${ }^{4}$}

\author{
${ }^{1}$ Department of Gerontological Nursing, South Valley University, Egypt. \\ ${ }^{2}$ Department of Community Health Nursing, Faculty of Nursing, Assuit University, Egypt. \\ ${ }^{3}$ Department of Epidemiology and Biostatistics, School of Public Health, Curtin University, Australia. \\ ${ }^{4}$ Department of Food Science \& Technology, Faculty of Agriculture, Assiut University, Egypt.

\section{* Correspondence:} \\ E-mail: drnadia.abdelnaser@ nurs.svu.edu.eg \\ Postal address: South Valley University, Faculty of Nursing, Department of Gerontological Nursing, Qena, \\ 83523, Egypt
}

\begin{abstract}
Background: Immunity age related changes make elderly riskier for infectious diseases. Consequently, it increases morbidity, irreversible frailty and dependency. Diet is recognized to modulate immune functions in several modes and to affect host resistance to infections.

Objective: The study aimed to improve the knowledge of older adults about the nutritional elements and its sources that support and increase the immune response.
\end{abstract}

Research design: Quasi experimental research design.

Setting: The study was conducted at an elderly club at Qena city, Egypt.

Subjects: A convenient sample of 106 older adults from an elderly club was randomly assigned equally into either the intervention group or the control group.

Method: The educational sessions were implemented over five weeks. Knowledge on nutritional elements were measured at baseline, immediately after the intervention and three months later.

Results: Immediately after the intervention, the percentage of elderly with 'good' knowledge increased from $0 \%$ to $90 \%$ in the intervention group $(\mathrm{p}=0.001)$. While this dropped to $46 \%$ at follow up, percentage of elderly in the intervention group with 'fair' knowledge was high at $48 \%$. Agerelated cognitive ability might have contributed to this difference.

Conclusion: The nursing intervention improved knowledge and nutritional habits of the elderly.

Keywords: Educational program, Nutrition, Older adults, Immunity

\section{Key points}

- Quasi experimental research was used to conduct the nursing educational sessions about knowledge of older adults regarding nutrition that enhance immunity.

- The nursing educational intervention is effective for improving knowledge about nutrition that enhance the immunity among elderly

- There was no statistically significant differences between subjects' level of knowledge at pre, post, and follow up test $(\mathrm{P}$-value $=0.939)$ in the control group.

- The vast majority of the subjects (94.0\%) had poor knowledge level at pre-test (baseline) which reduced to zero at immediate post-test.

\begin{tabular}{|c|c|c|}
\hline Receive Date : $25 / 11 / 2020$ & Accept Date: $28 / 11 / 2020$ & Publish Date : $1 / 12 / 2020$ \\
\hline
\end{tabular}




\section{Introduction}

Aging is described as a series of processes that promote vulnerability to challenges, thereby increases the likelihood of death (1). There is evidence that frail immunity can increase the probability of death (2). Immunesenescence (immunity age related changes) is an important part of the aging process $(\underline{\mathbf{3}}, \underline{\mathbf{4}})$. Immunesenescence increases susceptibility to infectious diseases such as influenza and pneumonia which leads to morbidity, irreversible frailty and dependency (5). These burdens in developing countries such as Egypt is a major public health challenge and cost (6).

Nutrition is one of many interrelated factors with immunesenescence. The role of both macronutrients and micronutrients in the immune response as well as their deficiency has been reported by researchers $(\underline{\mathbf{3}}, \underline{\mathbf{7}})$. Studies reported the association between undernutrition and protein deficiency and declines in immunity' parameters (specific and non-specific) such as a changed number of $\mathrm{T}$ cells, phagocytic cells, and secretory immunoglobulin (Ig) A antibody response (8, 9). The interactions between nutrition and the immune system have clinical, practical, and public health importance $(\underline{\mathbf{7}}, \underline{\mathbf{1 0}})$.

In Egypt, many studies confirmed that the micronutrient (minerals and vitamins) intake was found to be lower than the recommended dietary allowance among elderly people who have poor nutritional status (11-13). According to the World Health Organization (WHO), the proportion of old individuals (over the age of 60 years) will rise to $22 \%$ of the world population by 2050 (14). Regarding, State Information Service (SIS), Egypt is rapidly aging in its demographic structure. The total percent of older adults aged 60 years and above has increased to 6.9 in 2016 from 6 percent in 2010 (15). According to WHO, the life expectancy in Egypt also increased to 69 years for male and 73 years for female (16) .

Many research in Egypt assessed the older adults' nutritional status and found that elderly nutritional intake is unsatisfactory and lower than recommended dietary allowance due to lack of knowledge $(\underline{\mathbf{1 1}}, \underline{\mathbf{1 2}}, \underline{\mathbf{1 7}})$. Many studies recommend that education intervention be introduced to increase immunity, prevent disease and promote health $(\underline{\mathbf{1 8}}, \underline{\mathbf{1 9}})$.

Although researchers showed that nutritional educational intervention is needed in Egypt to improve nutritional intake of elderly in order to improve their immunity, there is a lack of nutrition education intervention among elderly in Egypt (20-22$)$. This study aimed to increase older adults knowldeg about the nutrition that enhance their immunity by implementing an educational intervention. The knowledge of older adults about the nutritional elements and its sources that support and increase their immune 
response was evaluated as the outcome at Qena city.

\section{SUBJECTS AND METHOD}

A) Research design: Quasi experimental research design.

B) Research hypothesis: Knowledge of the community-dwelling older adults on nutrition and immune functions will increase after completion of the program.

C) Setting: The study was conducted at an elderly club, the only elderly club at Qena city, Egypt. The club provides many services for older adults from any socioeconomic class, including recreational activities and health services (medical \& physiotherapy).

\section{D) Sample size:}

\section{- Sample selection technique}

A convenient sampling technique was used to recruit participants. The study included all elderly members at Qena Elderly club from both sex according to the following inclusion criteria:

1. Aged 60 years and older.

2. Free from any mental diseases according to their score of MiniMental State Examination scale (he/she must obtain 24-30 score).

E) Tool of the study: Structured interview form:

This tool was developed by the researcher based on relevant literature. Applicability and clarity of the tool was tested for its content validity by five nursing and medical experts in the related fields and it was valid 0.96.

Concerning validity calculation, the total number of the tool questions are 55 and each question was rated from 1 to 5 degree.

Validity equation is the total number of questions which got 3 to 5 degree from each one of the jury committee $(54+52+53+51$ $+54=264$ ) divided by the total number of the questions multiple by jury numbers $(55 \times 5=$ 275).

Validity $=264 \div 275=0.96$

Its reliability was measured by Cronbach's Alpha and it was reliable 0.90 . This tool was translated into Arabic by the researcher. It consists of three parts.

\section{Part one: Socio-demographic data:}

This part contains a set of questions concerning socio-demographic data such as age, sex, marital status, income, residence and level of education of the elderly.

Part two: Knowledge of older adults regarding immune system.

This part includes a set of questions concerning immune system, immunity response, and age-related changes in the immune system and type of immunity.

Part three: Knowledge of older adults regarding nutritional elements that enhance immunity:

This part includes a set of questions concerning macronutrients and micronutrients that enhance the immunity, and other food which has vital effects on immunity such as the 
best sources of carbohydrate, and benefits of carbohydrate in the immunity.

Questions related to knowledge level (part two and three) contains eleven open questions (which were scored as incorrect answer $=0$, incomplete but correct answer $=1$ and complete and correct answer $=2$ ) and fortyfour multiple choice questions (scored according to the number of correct answers). The maximum score is 90 points. Knowledge points were categorized into three categories:

- Poor knowledge ( $<50 \%$ correct)

- Fair knowledge (50-69 \% correct)

- Good knowledge ( $\geq 70 \%$ correct).

\section{The Health Education Program}

The educational program was developed and implemented by the researcher for older adult's knowledge regarding nutrition that enhances their immunity. Booklet, brochures, and posters were used to clarify the information. The information was designed to suit the older adults' abilities and capabilities using large bold font and colours with high contrast for older adults to see and read easily. The information also contained images with true and false signs to suit illiterate participants.

\section{A. Implementation phase:}

The intervention group was divided into two groups; male group (29) and female group (24). The researcher gave the sessions in 2 days for male group and other 2 days for female group per week. The educational program was implemented over five weeks.
The total number of intervention group was 53 in the intervention group but three of them dropped out after the second session so, 50 participants completed the study. The total number of sessions was 10 ; one session per day and two sessions per week for each intervention group. Each session continued for about one and a half hour. The total sessions time was 15 hours for each intervention group. The control group attended only at the time of pre-test, posttest and follow up test. The research motivated the subjects in both groups by free measuring blood pressure and blood glucose level every time for each elderly.

\section{B. Evaluation phase:}

Immediately after the five-week intervention, knowledge about immune system and nutritional elements that enhance the immunity was measured in both groups. At the three-month follow-up, the same tool was used to assess knowledge about immune system and nutritional elements that enhance the immunity.

Ethical consideration: The study was approved by the College of Nursing, Assiut University, Egypt. Permission to carry out the study was obtained from the Director of the elderly club after explaining the purpose of the study. Because obtaining a written consent in Egypt is so difficult, a verbal consent from elders to participate in the study was obtained after explanation of the study purpose.

- Each elderly person was assured about the confidentiality of the collected data. 
The privacy of each elderly patient was maintained. There was no risk to the participants from attending the educational sessions or using the study tools.

\section{Statistical analysis}

Data were collected on paper documents, uploaded to Microsoft Excel for storage, and transferred to STATA, version 12, for analysis.

Descriptive statistics of gender, marital status, and educational level, were described using frequency. Knowledge level of poor, fair and good was described using frequency (n) and percentage (\%). Chi-square $\left(x^{2}\right)$ and Fisher exact tests were used to test associations between the categorical variables and significance was considered at $\mathrm{p}<0.05$. Independent sample T-test was used to test if the knowledge score was different between the two groups.

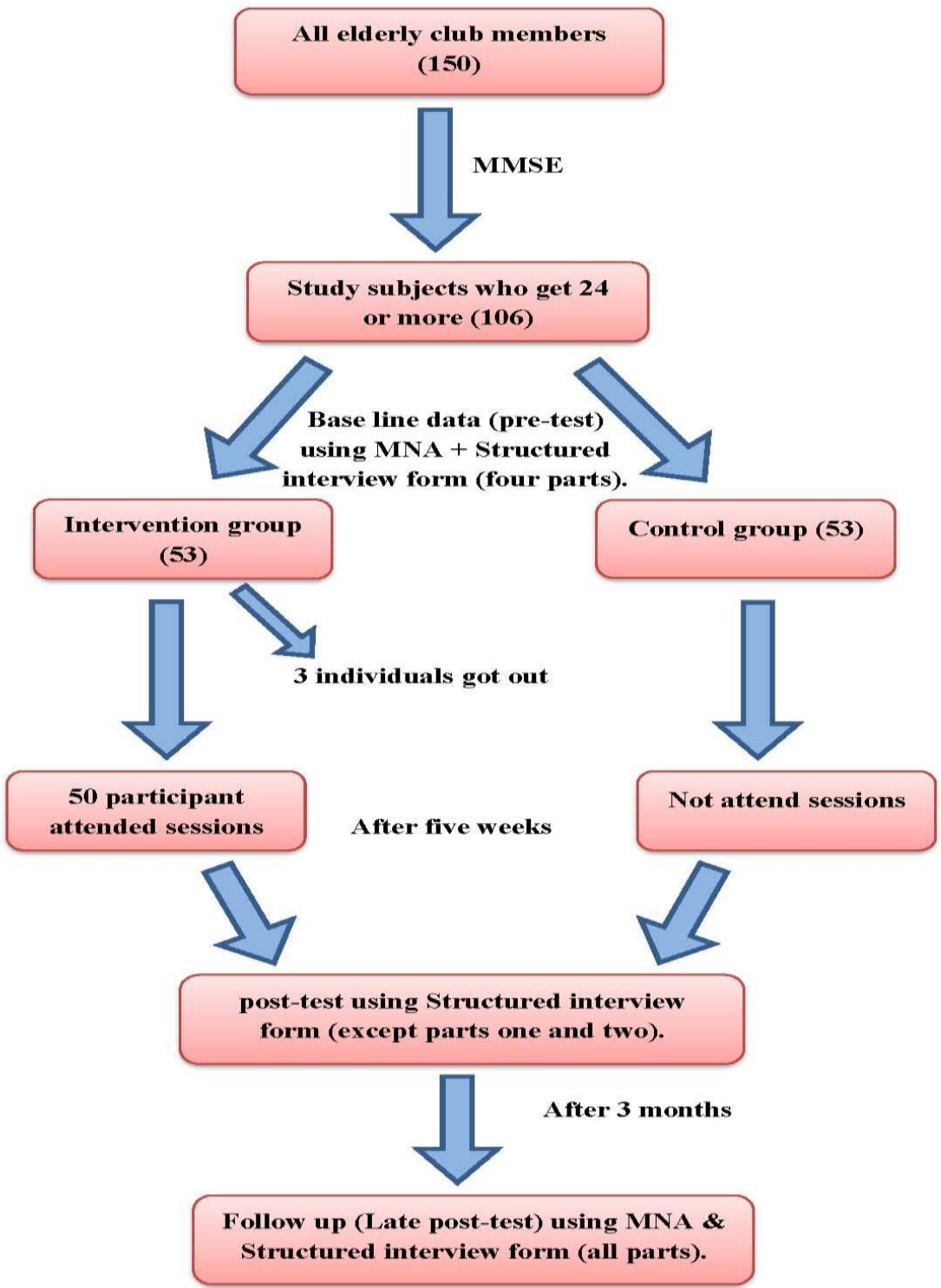

Figure 1: Recruitment process 


\section{Results}

Part I: Sociodemographic characteristics of the study subjects Table 1 Sociodemographic characteristics of the study subjects.

\begin{tabular}{|c|c|c|c|c|c|c|}
\hline \multirow[t]{2}{*}{ Sociodemographic characteristics } & \multicolumn{2}{|c|}{$\begin{array}{l}\text { Intervention } \\
\text { Group } \\
(\mathbf{n}=\mathbf{5 0})\end{array}$} & \multicolumn{2}{|c|}{$\begin{array}{l}\text { Control } \\
\text { Group } \\
(n=53)\end{array}$} & \multirow[t]{2}{*}{$\chi^{2}$} & \multirow[t]{2}{*}{ p-value } \\
\hline & No. & $\%$ & No. & $\%$ & & \\
\hline \multicolumn{7}{|l|}{ Age (years old): } \\
\hline 60 to 64 & 27 & 54.0 & 23 & 43.4 & \multirow[b]{2}{*}{1.1581} & \multirow[b]{2}{*}{0.282} \\
\hline$\geq 65$ & 23 & 46.0 & 30 & 56.6 & & \\
\hline \multicolumn{7}{|l|}{ Sex: } \\
\hline Male & 28 & 56.0 & 23 & 43.4 & \multirow[b]{2}{*}{1.6350} & \multirow[b]{2}{*}{0.201} \\
\hline Female & 22 & 44.0 & 30 & 56.6 & & \\
\hline \multicolumn{7}{|l|}{ Marital status: } \\
\hline Married & 40 & 80.0 & 37 & 69.8 & \multirow[b]{2}{*}{1.4153} & \multirow[b]{2}{*}{0.234} \\
\hline Widowed & 10 & 20.0 & 16 & 30.2 & & \\
\hline \multicolumn{7}{|l|}{ Educational level: } \\
\hline Illiterate & 15 & 30.0 & 19 & 35.9 & \multirow{3}{*}{5.6811} & \multirow{3}{*}{0.058} \\
\hline $\begin{array}{l}\text { Less than secondary (includes Able to } \\
\text { read \& write, and primary level). }\end{array}$ & 10 & 20.0 & 19 & 35.9 & & \\
\hline Secondary and high & 25 & 50.0 & 15 & 28.3 & & \\
\hline \multicolumn{7}{|l|}{ Occupation before retirement: } \\
\hline House wife & 17 & 34.0 & 24 & 45.3 & \multirow{3}{*}{1.4780} & \multirow{3}{*}{0.478} \\
\hline Office work (employee) & 25 & 50.0 & 23 & 43.4 & & \\
\hline Manual work (skilled, farmer) & 8 & 16.0 & 6 & 11.3 & & \\
\hline \multicolumn{7}{|l|}{ Monthly income: } \\
\hline Adequate & 27 & 54.0 & 41 & 77.4 & \multirow[b]{2}{*}{6.2574} & \multirow[b]{2}{*}{$0.012 *$} \\
\hline Inadequate & 23 & 46.0 & 12 & 22.6 & & \\
\hline \multicolumn{7}{|l|}{ Residence: } \\
\hline Rural & 29 & 58.0 & 22 & 41.5 & \multirow[b]{2}{*}{2.7989} & \multirow[b]{2}{*}{0.094} \\
\hline Urban & 21 & 42.0 & 31 & 58.5 & & \\
\hline
\end{tabular}

* Significant at $<0.05$

Sociodemographic characteristics of the intervention and the control group were showed in table 1 . The demographics of the two groups were similar except for monthly income $(p=0.012)$. More of the elderly from the control group had 'adequate' monthly income.

Figure 2 illustrates the level of subjects' knowledge at baseline, immediate post, and 3- month follow up within the intervention group and the control group. Within intervention group, it is noticed that, the vast majority of the subjects $(94.0 \%)$ had poor knowledge level at pre-test (baseline) which reduced to zero at immediate post-test. Also, no one had good level of knowledge at pre-test but this level raised to ninety percent $(90.0 \%)$ at immediate post-test. Such knowledge in retained at the 
3-month follow up among nearly half of the subjects $(46 \%)$ while level of fair knowledge improved from $10 \%$ at immediate posttest to $48 \%$ at 3-month follow up. These changes are statistically significant $(p$-value $=0.001)$ There

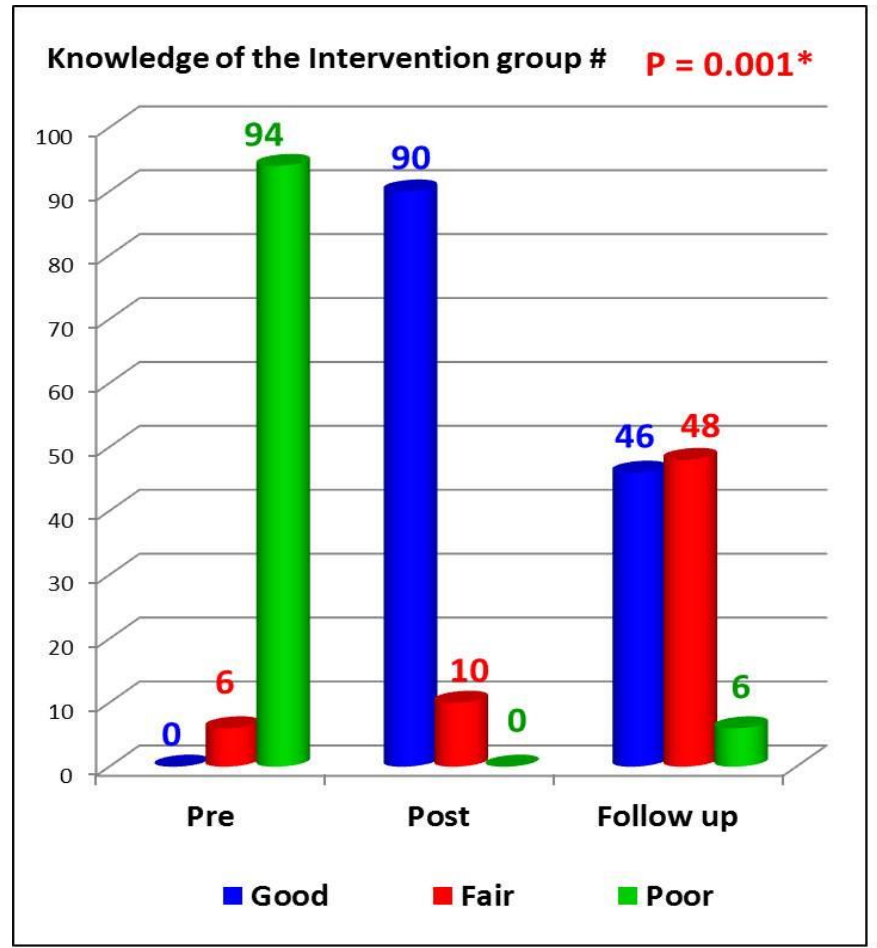

was no statistically significant differences between subjects' level of knowledge at pre, post, and follow up test $(\mathrm{p}$-value $=0.939)$ in the control group.

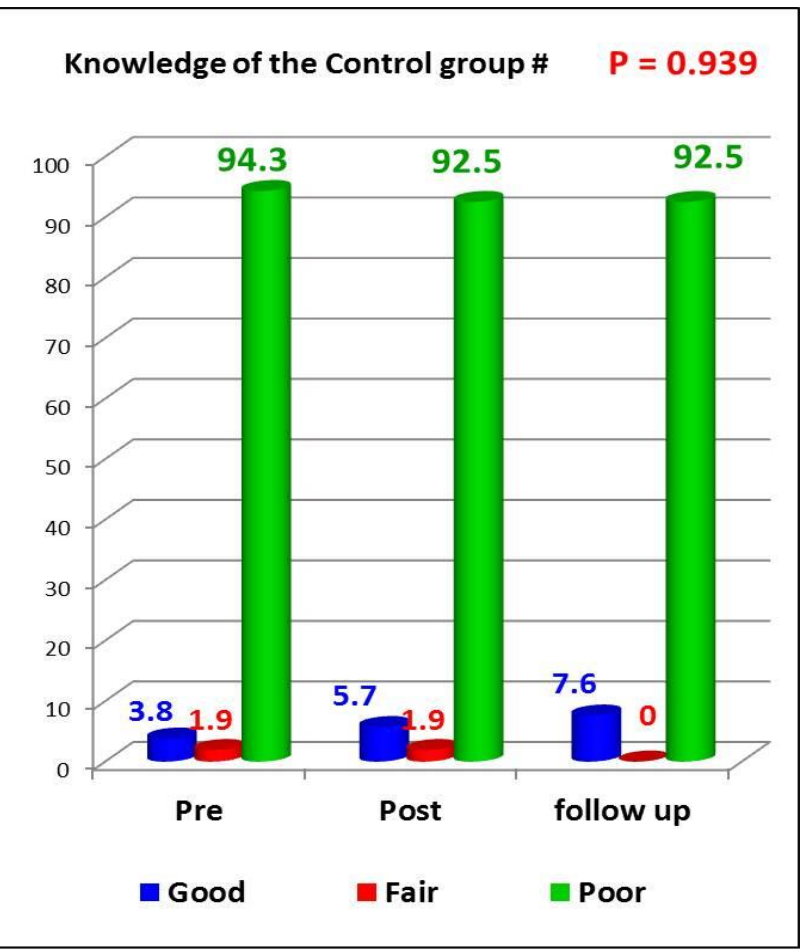

* $\mathrm{P}$ value be significant at $\leq 0.05$ and it is from fisher exact test.

\# Knowledge of subjects about immunity and how nutrition enhance immunity.

Poor $<50 \%$ correct answers, Fair $=50$ to $<75 \%$, Good $=75 \%$ to higher.

Figure 2 Knowledge about nutrition that enhance the immunity of the intervention and the control groups across three time points

Table 2 Mean difference of knowledge score (post-pre, follow up - pre) between the intervention and control group.

\begin{tabular}{|c|c|c|c|c|c|c|}
\hline \multirow{3}{*}{ Group } & \multicolumn{6}{|c|}{ Difference of knowledge score } \\
\hline & \multicolumn{3}{|c|}{ Post - pre } & \multicolumn{3}{|c|}{ Follow up- pre } \\
\hline & Mean & $95 \% \mathrm{CI}$ & p-values* & Mean & $95 \% \mathrm{CI}$ & p-values * \\
\hline Intervention & 4.05 & $3.96: 4.13$ & \multirow{2}{*}{$0.001 *$} & 3.86 & $3.78: 3.95$ & \multirow{2}{*}{$0.001 *$} \\
\hline Control & 2.00 & $1.42: 2.58$ & & 1.57 & $1.01: 2.12$ & \\
\hline
\end{tabular}

$*$ p $<0.05$ as reported from independent samples t-test after transformation using natural logarithm.

Mean difference of knowledge score (post-pre, follow up - pre) between the intervention and control group is shown in Table 2. Difference between the intervention and control group at both "post-pre" and "follow up -pre" were significant $(\mathrm{p}$-values $=0.001$ for both $)$. 
Table 3 Association between age categories and knowledge level of the study subjects.

\begin{tabular}{|c|c|c|c|c|c|c|c|c|c|c|c|c|c|c|c|}
\hline \multirow{4}{*}{$\begin{array}{l}\text { Age } \\
\text { categories }\end{array}$} & \multirow{4}{*}{ Test } & \multicolumn{14}{|c|}{ Knowledge level } \\
\hline & & \multicolumn{7}{|c|}{ Intervention group $\mathrm{N}=\mathbf{5 0}$} & \multicolumn{7}{|c|}{ Control group $N=53$} \\
\hline & & \multicolumn{2}{|c|}{ Poor } & \multicolumn{2}{|c|}{ Fair } & \multicolumn{2}{|c|}{ Good } & \multirow{2}{*}{$\begin{array}{c}\text { p- } \\
\text { value } \\
*\end{array}$} & \multicolumn{2}{|c|}{ Poor } & \multicolumn{2}{|c|}{ Fair } & \multicolumn{2}{|c|}{ Good } & \multirow{2}{*}{$\begin{array}{c}\text { p- } \\
\text { value * }\end{array}$} \\
\hline & & No & $\%$ & No & $\%$ & No & $\%$ & & No & $\%$ & No & $\%$ & No & $\%$ & \\
\hline $\begin{array}{ll}\text { From } & 60 \\
\text { to } 64 & \end{array}$ & \multirow{2}{*}{ Pre } & 26 & 55.3 & 1 & 33.3 & 0 & 0.0 & \multirow{2}{*}{0.588} & 21 & 42 & 0 & 0.0 & 2 & 100.0 & \multirow{2}{*}{0.184} \\
\hline $\begin{array}{l}\text { From } 65 \\
\text { and above }\end{array}$ & & 21 & 44.7 & 2 & 66.7 & 0 & 0.0 & & 29 & 58 & 1 & 100.0 & 0 & 0.0 & \\
\hline $\begin{array}{ll}\text { From } & 60 \\
\text { to } 64 & \end{array}$ & \multirow{2}{*}{ Post } & 0 & 0.0 & 3 & 60.0 & 24 & 53.3 & \multirow{2}{*}{1.000} & 20 & 40.8 & 0 & 0.0 & 3 & 100.0 & \multirow{2}{*}{0.076} \\
\hline $\begin{array}{l}\text { From } 65 \\
\text { and above }\end{array}$ & & 0 & 0.0 & 2 & 40.0 & 21 & 46.7 & & 29 & 59.2 & 1 & 100.0 & 0 & 0.0 & \\
\hline $\begin{array}{ll}\text { From } & 60 \\
\text { to } 64 & \end{array}$ & \multirow{2}{*}{$\begin{array}{l}\text { Follow } \\
\text { up }\end{array}$} & 1 & 33.3 & 9 & 37.5 & 17 & 73.9 & \multirow{2}{*}{$\begin{array}{c}0.024 \\
*\end{array}$} & 20 & 40.8 & 0 & 0.0 & 3 & 75.0 & \multirow{2}{*}{0.305} \\
\hline $\begin{array}{l}\text { from } 65 \\
\text { and above }\end{array}$ & & 2 & 66.7 & 15 & 62.5 & 6 & 26.1 & & 29 & 59.2 & 0 & 0.0 & 1 & 25.0 & \\
\hline
\end{tabular}

Among the intervention group, as shown in Table 3, there is no significant association found between age categories and knowledge levels at both pre-and postmeasurements ( $\mathrm{p}>0.05)$. However, a statistical significant association between age categories and knowledge levels at the 3-month follow-up was noted ( $\mathrm{p}$-value $=$ 0.024) where more 60-64 years old elderly had 'good' knowledge than those 65 years old or older. No significant association between age categories and knowledge levels were found for the control group at all the three time points $(\mathrm{p}>0.05)$.

\section{Discussion}

Nutrition plays a pivotal role in health promotion, diseases prevention, and chronic diseases management. It is the first line to maintain and improve the immunity of older adults $(\underline{\mathbf{3}}, \underline{\mathbf{2 5}}, \underline{\mathbf{2 6}})$. Studies in less developed Arab countries especially Egypt had confirmed that nutritional habits are unhealthy among young and old people and that they lack knowledge about healthy diet that enhance the immunity. Meanwhile, there is a lack of health educational program about nutrition and healthy nutritional habits that enhance the immunity $(\underline{\mathbf{1 1}}, \underline{\mathbf{1 2}}$, 17).

The present study reported that the nursing educational intervention is effective for 
improving knowledge about nutrition that enhance the immunity among older adults. The effectiveness happen after one month however after 3 months the recovery fall almost a half. This is evidenced by first; at Pre-test, most of the intervention participants didn't know the relation between nutrition and immunity, the nutrients types, protein sources, protein benefits to immunity, the best protein sources to immunity, the best sources of carbohydrate for immunity, effects of carbohydrate on immunity, fiber sources, fiber effects on immunity, the effects of heating on fats, useful fat sources, omega 3, 6 sources, the most common vitamin B, A, and E sources, the most common sources of iron, selenium, calcium \&magnesium, and zinc, the effects of garlic, honey, olive oil and black cumin on the immunity while at post-test, most of the intervention participants known well the previous mentioned knowledge items.

Similar to the present study, Hegazy et al (2013) conducted their study at El Haram dialysis Centre, Giza, Egypt to identify malnutrition problems and assess the effect of dietary counseling on improvement of health status of end-stage renal disease elderly patients aged 60 years and above. There were improvements in all items of knowledge post-intervention. "Don't know" responses decreased dramatically from $82.9 \%$ to only $5.4 \%$ after the intervention (22).

According to the following studies in United states, the nutritional education program improves the nutritional knowledge of the older adults the same as reported in this study. Jung (2014) has implemented the program, " Journey through Health " using the Health Belief Model and provided information on how the overarching Dietary Guideline Consumer Brochure messages can positively influence nutrition and physical activity choices. Nearly two thirds of participants increased their rankings of the four questions evaluating older adults' perceived benefit of nutrition and physical activity in health promotion (27). Kim et al (2012), assessed the improvement in nutritional status following the application of nutrition education program to elderly patients in a long-term care hospital and they concluded that of the twelve questions, scores for ten increased with statistical significance $(\mathrm{P}<0.05)(\underline{\mathbf{1 9}})$.

Second; dramatically increasing knowledge level of the vast majority of intervention group from poor level at pretest to good level at post-test and nearly half of them maintaining fair level at follow-up with highly statistically significance. The same finding was confirmed by El-sol et al (2016), who conducted their study at 
Menoufia University Hospital, Egypt to determine the effect of educational nursing intervention about osteoporosis on knowledge of older adults. They confirmed that all of the studied subjects had inadequate knowledge in the pre educational intervention while after the nursing educational intervention program, three quarters of them were adequately educated, and only quarter were inadequately educated (20)

Third; the mean difference of knowledge score (post-pre, follow up-pre) between intervention and control group indicates highly significance $(\mathrm{P}=\mathbf{0 . 0 0 1})$ which means that the intervention participants gain more knowledge from the program sessions and their knowledge score increase at post-test compared to baseline score and at followup test compared to baseline score too. The high level of participation and interest in this study may also suggest that participants were highly interested to improve their nutrition knowledge and dietary habits to improve their immunity and nutritional status as mentioned by most of them. This finding is in agreement with previous study in which Abd Allah et al (2015) assessed the effectiveness of diet therapy program on dietary knowledge and practice of 90 elderly patients at Zagazig University Hospitals, Egypt. The researchers reported that the total knowledge of the elderly patients showed statistically significant improvements after the intervention $61.1 \%$ ) compared with $18.9 \%$ before intervention ( $\mathrm{p}<0.001)(\underline{\mathbf{2 1}})$.

At the three-month follow up, significant association between knowledge levels and age groups, were observed in this present study. This can be explained by the agerelated reduction in memory functions.

\section{Limitation of the study}

There are a few limitations of the present quasi-experimental study. Firstly, this was done in one single location. Secondly the follow-up period was relatively short. Nevertheless, the study used validated tool and had good participation rate, suggesting it has good internal validity.

\section{Conclusion}

Based on the results of the present study, it was concluded that the nursing intervention improved knowledge and nutritional habits of the elderly in a short time after intermediation. The knowledge level increased after completing the nutritional intervention among the study group.

\section{Declaration}

\section{Consent for publication}

N/A

\section{Availability of data and materials}

The datasets used and analyzed during the current study are available from the corresponding author on reasonable 
request.

\section{Competing interests}

The authors declare that they have no competing interests.

\section{Funding}

This research did not receive any specific grant from funding agencies in the public, commercial, or not-for-profit sectors.

\section{Authors' contributions}

- Nadia Omar Emam Abdelnasser assigned the study tool (structured interview form), collected, entered, and analyzed data, and wrote the manuscript.

- $\quad$ Prof. Hoda Diab Fahmy Ibrahim revised the study tool as well as the whole

\section{References}

1. Eliopoulos C: Gerontological Nursing $8^{\text {th }}$ ed. lippincott williams \& wilkins 2015.

2. Wordsworth D, Dunn-Walters DK: The ageing immune system and its clinical implications. Reviews in Clinical Gerontology 2010, 21(2):110-24.

3. Pae M, Meydani SN, Wu D: The Role of Nutrition in Enhancing Immunity in Aging. Aging and Disease 2012,3(1):91-129.

https://www.ncbi.nlm.nih.gov/pmc/article s/PMC3320807/

4. Khalyavkin A, Krut'ko V: Early Thymus Involution - Manifestation of an Aging Program or a Program of Development? Biochemistry (Moscow) 2015, 80(12):1622-1625. https://doi.org/10.1134/S000629791512 $\underline{0111}$ manuscript.

- $\quad$ Dr HuiJun Chih provided statistical consultation to the analyses, assisted in the interpretation of the results and contributed to the draft of the manuscript.

- Dr Asmaa Kamal Hassan revised the manuscript.

- $\quad$ Prof. Mohamed Kamal Alsayed Youssef suggested the design of the study.

\section{Acknowledgements}

The authors acknowledge all participants of the study and the administrative staff of Elderly Club for their cooperation and help.

5. YongChao M, Min F: Immunosenescence and age-related viral diseases. Science China Life Sciences 2013, 56(5):399-405. https://doi.org/10.1007/s11427-0134478-0

6. Boraschi D, Aguado MT, Dutel C, Goronzy J, Louis J, Grubeck-Loebenstein B, Rappuoli, Rino, Del Giudice G: The Gracefully Aging Immune System. Science Translational Medicine 2013, 5(185): $185 \mathrm{ps} 188$.

Doi: 10.1126/scitranslmed.3005624.

7. Oketch JA, Paterson M, Maunder EW, Rollins NC: Too little, too late: Comparison of nutritional status and quality of life of nutrition care and support recipient and non-recipients among HIV-positive adults in KwaZuluNatal, South Africa. Health Policy 2011, 99(3):267-276.

https://doi.org/10.1016/j.healthpol.2010.0 $\underline{8.018}$ 
8. Arvanitoyannis I: Irradiation of Food Commodities: Techniques, Applications, Detection, Legislation, Safety and Consumer Opinion $1^{\text {st }}$ ed. Boston: Academic Press 2010, 699-710 p.

9. Wong S: Scientists discover protein that boosts immunity to viruses and cancer. 2015, Retrieved 7 August, 2017 , from http://www3.imperial.ac.uk/newsandevent spggrp/imperialcollege/newssummary/ne ws 16-4-2015-14-51-47

10. Zapatera B, Prados A, GomezMartinez S, Marcos A: Immunonutrition: methodology and applications. Nutricion hospitalaria 2015, 31 Suppl 3:145-154. doi: 10.3305/nh.2015.31.sup3.8762

11. El-damhougy S, Hussein M, Abd Elazeem A: Dietary Intake and Biochemical Indicators of Nutritional Status in an Institutionalized Egyptian Elderly Population. Med J Cairo Univ. 2010,78(1):385-391

12. Ibrahim H, El Kady H, Elsayed D: Factors Affecting Nutritional Status among Elders Attending Geriatric Clubs in Alexandria, Egypt. Journal of American Science 2013, 9(10):183-192. doi: $10.7537 /$ marsjas091013.24

13. Esmayel EMM, Eldarawy MM, Hassan MMM, Hassanin HM, Reda Ashour WM, Mahmoud W: Nutritional and Functional Assessment of Hospitalized Elderly: Impact of Sociodemographic Variables. Journal of Aging Research 2013, 2013:101725. http://dx.doi.org/10.1155/2013/101725

14. WHO: Ageing and life course. www.who.int/ageing/en/index.html/ ;2015 Accessed 13 June, 2017.

15. State Information Service. Egypt in Figures 2016, Population. http://www.sis.gov.eg/Story/64485?lang= ar 2016 Accessed 6 June, 2017.
16. WHO: Egypt, Statistics. http://www.who.int/countries/egy/ar/ 2015 Accessed 6 June, 2017.

17. Al Riyami A, Al Hadabi S, Abd El Aty MA, Al Kharusi H, Morsi M, Jaju S: Nutrition knowledge, beliefs and dietary habits among elderly people in Nizwa, Oman: Implications for policy. Eastern Mediterranean Health Journal 2010, 16(8):859-867.

18. Queen M: Older adults' knowledge regarding HIV/AIDS. USA: Department of Family and Consumer Sciences, California State University; 2014.

19. Kim BH, Kim M-J, Lee Y: The effect of a nutritional education program on the nutritional status of elderly patients in a long-term care hospital in Jeollanamdo province: health behavior, dietary behavior, nutrition risk level and nutrient intake. Nutrition Research and Practice 2012 , 6(1):35-44.

https://doi.org/10.4162/nrp.2012.6.1.35

20. El-sol A, Abd Elhy A, Abd Elsalam E: Effect of Educational Nursing Intervention About Osteoporosis on Adult's Knowledge. American Journal of Nursing Science 2016,5(6):272-279. doi: 10.11648/j.ajns.20160506.16.

http://article.sciencepublishinggroup.com/ html/10.11648.j.ajns.20160506.16.html

21. Abd Allah E, Oraby E, Ibrahim R: Effect of Diet Therapy Program on Dietary Knowledge and Practice of Elderly Patients on Regular Hemodialysis. American Journal of Nursing Science2015,4(3):131137.doi:10.11648/j.ajns.20150403.23.

http://article.sciencepublishinggroup.com/ $\underline{\mathrm{html} / 10.11648 . j . a j n s .20150403 .23 . \mathrm{html}}$

22. Hegazy IS, El Raghy HA, AbdelAziz SB, Elhabashi EM: Study of the 
effect of dietary counselling on the improvement of end-stage renal disease patients. Eastern Mediterranean health journal 2013, 19(1):45-51. PMID: 23520905

23. Folstein MF, Folstein SE, McHugh PR: "Mini-mental state". A practical method for grading the cognitive state of patients for the clinician. J Psychiatr Res. 1975, 12(3):189-198. PMID: 1202204

\section{Abd-Elaziz S: Effect of Nursing Intervention for Cognitive} Rehabilitation among Elderly Patients with Stroke at Assiut Unversity Hospital. Unpublished thesis: Assuit University, Faculty of Nursing 2014.
25. Doan $\mathrm{T}$, Melvold R, Viselli $\mathrm{S}$, Waltenbaugh C: Immunology $2^{\text {nd }}$ ed. Philadelphia; Wolters Kluwer Health/Lippincott Williams \& Wilkins; 2013.

26. Abbas A, Lichtman A, Pillai S: Basic Immunology $4^{\text {th }}$ ed. UNITED STATES: Elsevier Health Sciences; 2012

27. Jung SE, Hermann J, Parker S, Smith B: Development and Evaluation of a Health Promotion Program for Older Adults: Journey Through Health. Journal of Nutrition Education and Behavior 2014,46(4):S121. https://doi.org/10.1016/j.jneb.2014.04.069 